\title{
Analysis of Dehumidification Effects on Cooling Capacity of an Evaporative Cooler*
}

\author{
Mohammad Hassan SAIDI**, Cyrus AGHANAJAFI*** \\ and Masoud MOHAMMADIAN**** \\ ${ }^{* \star}$ Mechanical Engineering Department, Sharif University of Technology, Tehran, Iran \\ ***Mechanical Engineering Department, K. N. T University of Technology, Tehran, Iran \\ ${ }^{* * \star *}$ Mechanical Engineering Department, Islamic Azad University South Tehran Branch, Tehran, Iran \\ E-mail: mmohamadian@pogc.ir
}

\begin{abstract}
In this study, effect of desiccant wheel, heat exchanger and cooling coil will be evaluated on decreasing the wet bulb temperature of entering air to cooling tower and decreasing the outlet cold water temperature. For this purpose, change effect of desiccant wheel parameters will be investigated on wet bulb temperature of outlet air from heat exchanger. After that, optimum parameters and minimum wet bulb temperature will be selected. Then, outlet cold water temperature will be achieved for various cooling coil surface temperature with definition of by pass factor and also by using optimum desiccant wheel parameters and entrance air wet bulb temperature to tower related to cooling coil surface temperature. To calculate wet bulb temperature, a mathematical model will be used that shows physical properties of air. After that a nomograph will be used to predict effect of decrease of entrance air wet bulb temperature on reducing the outlet water temperature and it will be done for several cities in Iran. At the end, an equation will be used to calculate required water to air mass flow rate for each outlet cold water temperature. With considering of known circulating water mass flow rate, required air for tower would be calculated and suitable desiccant wheel can be selected.
\end{abstract}

Key words: Desiccant Wheel, Wet Cooling Tower, Wet Bulb Temperature, Cooling Coil, Heat Exchanger

\section{Introduction}

In most industrial processes, large quantities of heat produce which must be permanently removed in order to maintain standard operating. Wet cooling towers are widely used to dissipate this heat. The advantage of wet cooling towers from other heat exchanger is that water in wet cooling towers will be cooled until wet bulb temperature of ambient air that is smaller than dry bulb temperature so water will be cooled more. On the other hand, if outlet water temperature from cooling tower decreases $0.55^{\circ} \mathrm{C}\left(1^{\circ} \mathrm{F}\right)$, energy consumption of other equipments that use from this water will reduce $3 \%$ and if this

${ }^{*}$ Received 8 Sep., 2009 (No. 09-0493) [DOI: 10.1299/jtst.5.151]

Copyright $(\mathcal{2} 2010$ by JSME 
temperature decrease to $1.67{ }^{\circ} \mathrm{C}\left(3^{\circ} \mathrm{F}\right)$, required energy of mentioned equipments will reduce $10 \%$. So it seems important to investigate on increasing the towers efficiency and decreasing the outlet water temperature. Cooling towers are used in various processes such as power generation units, chemical and petrochemical plants, refrigeration and air conditioning systems too, so optimization of wet cooling towers are important. On the other hand, desiccant wheels have been noticed crescive. This system can change psychrometric condition of own outlet air with moisture absorption. Since desiccant wheels allow the use of Low-temperature heat (Low-temperature industrial waste heat or solar energy) to regeneration, they attached increased attention. Kang and Maclain-Cross [1] showed that the dehumidifier is the key component of a desiccant cooling system and the cooling COP (coefficient of performance) can be significantly improved by improving the performance of this component. Maclain-Cross and Banks [2] developed an analogy method for predicting the coupled heat and mass transfer process in desiccant wheel. Consecutively, Banks [3] analyzed the coupled heat and mass transfer processes in a porous medium using a nonlinear analogy method and predicted the performance of a silica gel air dryer. Zheng and Worek [4] discussed the effect of rotary speed on the performance of the desiccant wheel by numerical simulation using an implicit finite differential method.

H. M. Hening et al. [5] evaluated the use of solar energy for regeneration of desiccant wheel and showed that energy consumption will reduce till $50 \%$ for cooling cycles. F. Esfandiari Nia et al. [6] solved coupled mass and energy equations and offered simple equations for outlet temperature and humidity of air from desiccant wheel. They also showed that the best temperature for regeneration of desiccant wheel is between $60-90{ }^{\circ} \mathrm{C}$. Vazirifard and M. H. Saidi [7] studied on importance of desorption and harm of disusing of it in Iran. H. Pasdarshahri et al.[8] studied on performance of desiccant cooling system and investigated on temperature, ambient humidity and regeneration temperature effects on COP, water consumption and outlet temperature of this system and showed that desiccant cooling systems can provide comfortable region in many cities of Iran.

Also Kachhwaha et al. [9] experimentally and theoretically studied a vertical evaporative cooler. The measured data were compared with the predicted results. Fisenko et al. [10] developed a mathematical model for predicting the performance of a cooling tower. The calculated results were validated by the measured data. J. R. Khan et al. [11] represented mathematical models for mass and heat transfer processes in cooling towers. P. Naphon [12] studied on cooling towers and showed that inlet water temperature has negligible effect on outlet water temperature. Guang-Yu Jin and Wen-Jian Cai [13] also represented a relation for outlet water temperature of cooling towers that contains ambient wet bulb temperature, inlet water temperature and a group of coefficients that these coefficients calculate from experimental data. Many researchers have studied on desiccant wheel and cooling towers but there is no study on effect of desiccant wheel upon wet cooling towers performance. The objective of this paper is to investigate desiccant wheel effect on decreasing the outlet water temperature of cooling tower. In this study a desiccant wheel, heat exchanger and a cooling coil will be used to reduce wet bulb temperature of entrance air to tower. After that various parameters of desiccant wheel will change to calculate outlet wet bulb temperature from heat exchanger by using optimum parameters of desiccant wheel. Outlet wet bulb temperature from cooling coil will be calculated for various surface temperature of that and this procedure will be done for various cities of Iran. 


\section{Nomenclature}

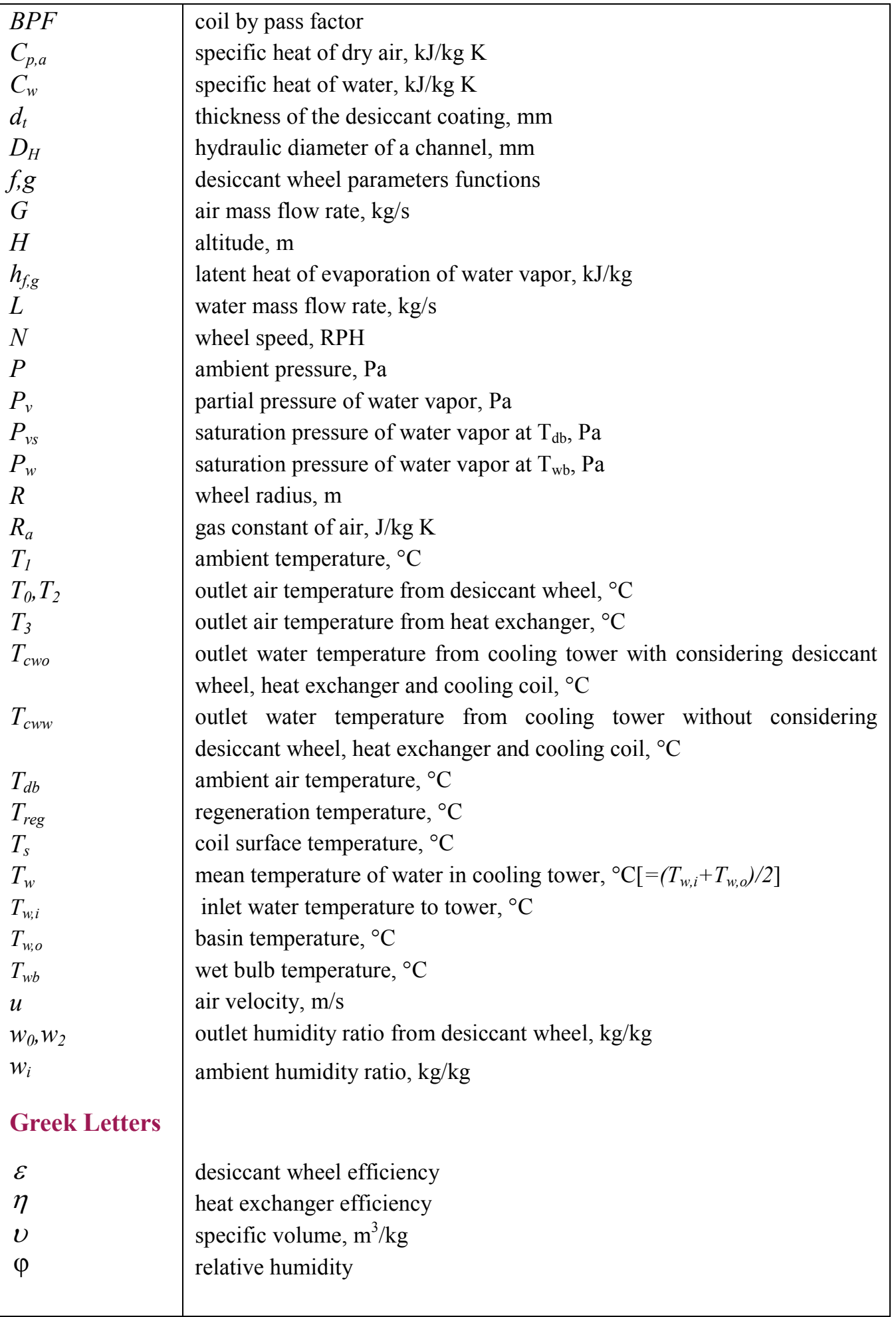

\section{Problem description}

In this study a desiccant wheel, heat exchanger and a cooling coil, will be used. Inlet wet bulb temperature for cooling tower will be calculated for various cooling coil surface temperature by selecting the desiccant wheel parameters in optimum quantities. The 
dehumidifier is a rotating cylindrical wheel of length $\mathrm{L}$ and radius $\mathrm{R}$ with small channels which walls are adhered with an adsorbent such as silica gel. Desiccant wheels are divided into two equal sections: the adsorbing section and the regeneration section (desorption of water vapor). The schematic of present system is illustrated in Fig.1. The aim of this system is to decrease ambient wet bulb temperature from point 1 to point 4 . This air will enter to tower to optimize tower performance and outlet water temperature will be compared with regard to time that the present system omitted. Fig.2 shows heat exchanger and coil effect on decreasing wet bulb temperature.

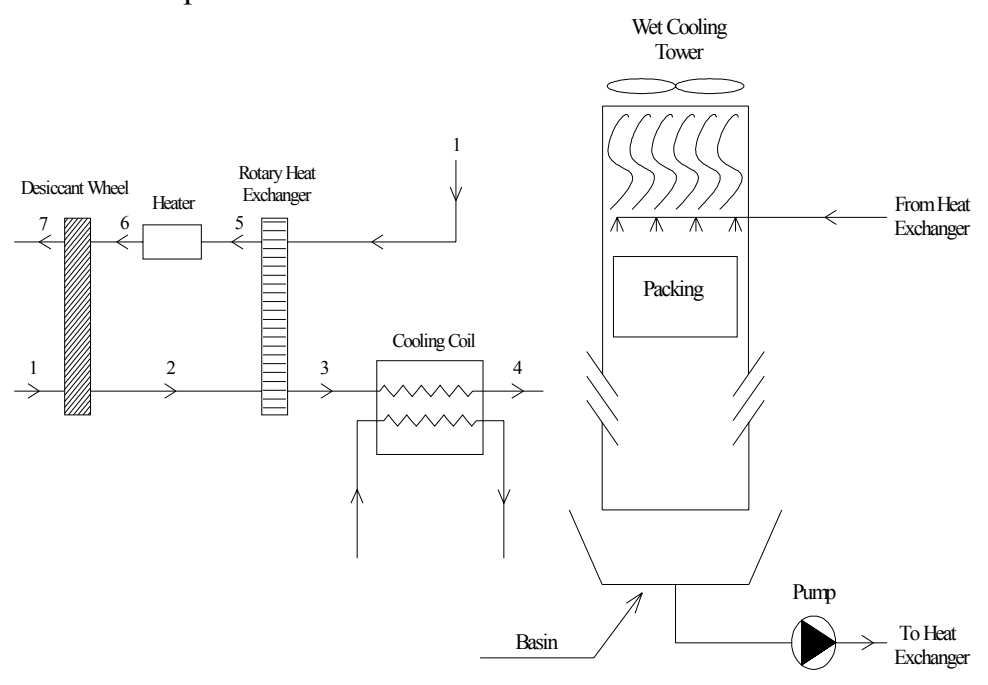

Fig.1 Schematic of air stream through

desiccant wheel, heat exchanger and coil

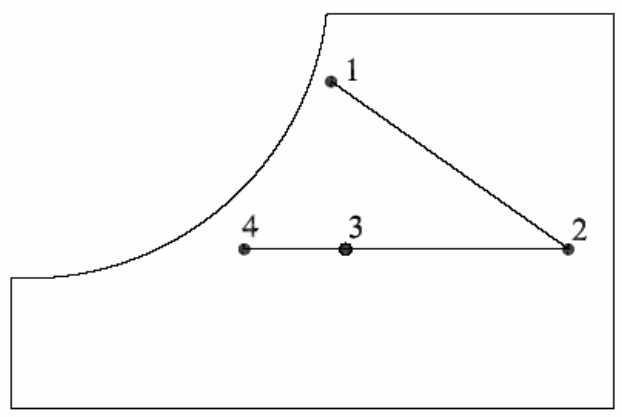

Fig.2 Schematic of air passing through desiccant wheel, heat exchanger and cooling coil on psychrometric chart $\left(T_{w b 4}<T_{w b 3}<T_{w b 1}\right)$

In Fig. 1 when desiccant wheel absorbs moisture, it must regenerate. For this purpose, existing system must have a heater to heat air. This air enters to wheel and regenerate that.

\section{Governing equations}

The most important section of present study is to calculate outlet air conditions from desiccant wheel. In this section, outlet temperature and humidity of outlet air from desiccant wheel will be calculated with using a mathematical model. This model is achieved by solving heat and mass transfer equations as follows [6]: 
$w_{0}=w_{2}=w_{i}-\varepsilon w_{i}$

$\varepsilon=f\left(T_{d b}\right) f\left(w_{i}\right) f(N) f\left(T_{r e g}\right) f\left(D_{H}\right) f\left(d_{t}\right) f(u)$

$T_{0}=T_{2}=g\left(T_{d b}\right) g\left(w_{i}\right) g(N) g\left(T_{r e g}\right) g\left(D_{H}\right) g\left(d_{t}\right) g(u)$

In Eq.(2) and Eq.(3), $f$ and $g$ are function of desiccant wheel parameters that functions f are as follows:

$$
\begin{aligned}
& f\left(T_{d b}\right)=-0.0001 T_{d b}^{2}-0.0031 T_{d b}+0.8353, \\
& f\left(w_{i}\right)=592.77 w_{i}^{2}-41.23 w_{i}+1.283 \\
& f(N)=-0.0001 N^{2}+0.0042 N+0.4474 \\
& f\left(T_{r e g}\right)=-0.0001 T_{r e g}^{2}+0.0355 T_{r e g}-0.4924 \\
& f\left(D_{H}\right)=-0.0572 \mathrm{D}_{H}^{3}+0.0933 D_{H}^{2}+0.6139 D_{H}-0.0922, \\
& f\left(d_{t}\right)=-21.67 d_{t}^{2}+6.93 d_{t}+1.34 \\
& f(u)=-0.0611 u+0.8376
\end{aligned}
$$

Also functions $\mathrm{g}$ are given by:

$$
\begin{aligned}
& g\left(T_{d b}\right)=-0.0001 T_{d b}^{2}+0.0275 T_{d b}+0.7993 \\
& g\left(w_{i}\right)=594.48 w_{i}^{2}+26.76 w_{i}+3.79 \\
& g(N)=-0.0002 N^{2}+0.0112 N+0.4201 \\
& g\left(T_{r e g}\right)=-0.0004 T_{r e g}^{2}+0.1255 T_{r e g}+0.6757 \\
& g\left(D_{H}\right)=-0.039 \mathrm{D}_{H}^{3}+0.026 D_{H}^{2}+0.603 D_{H}+0.0912, \\
& g\left(d_{t}\right)=-18.79 d_{t}^{2}+7.92 d_{t}+1.75 \\
& g(u)=-0.060 u+0.7973
\end{aligned}
$$

With using Eq. (4) and Eq. (5), outlet temperature and humidity from desiccant wheel, (point 2) will be calculated. After that heat exchanger's effect on outlet air from desiccant wheel, must be calculated (point 3). For this purpose a heat exchanger will use with efficiency equal $90 \%$ that related equation of it, is as follows:

$\eta=\frac{T_{2}-T_{3}}{T_{2}-T_{1}}$

The best situation $(\eta=100 \%)$ is when $\mathrm{T}_{3}$ would be equal to $\mathrm{T}_{1}$ that temperature of point 3 decrease until temperature of point 1 . But in fact, $T_{3}$ is equals to a temperature between $T_{1}$ and $T_{2}$ according to above expression.

In above equation, $T_{2}$ will calculate from Eq. (3) and $T_{1}$ is ambient temperature. By calculating the outlet temperature from heat exchanger, outlet temperature from cooling coil must be calculated (point 4). For this purpose a cooling coil with by 
pass factor equal 0.1 will be used that related equation for cooling coil by pass factor defines as follows:

$B P F=\frac{T_{4}-T_{s}}{T_{3}-T_{s}}$

BPF describes as follows:

For an ideal cooling coil, its BPF equals to zero because the temperature of outlet air decrease until $\mathrm{T}_{\mathrm{s}}$. In worst situation, all the air escapes from coil and its temperature remains in $T_{3}$. In this situation, BPF is equal to 1.

$\mathrm{T}_{\mathrm{s}}$ in above equation is cooling coil surface temperature. In the Fig. $2, w_{4}=w_{3}=w_{2}$ and by calculating the point 4's temperature from Eq.(7) and humidity of point 4 from Eq.(1), wet bulb temperature of point 4 can be calculated from a model that has been presented by M. A. AL-Nimr [14]. In this study, the mentioned model will be used and by means of trial and error, psychrometric conditions of air will be investigated that this model is given by:

$$
\begin{aligned}
& v=\frac{R_{a}\left(T_{d b}+273.15\right)}{P-P_{v}} \\
& w=0.622 \frac{P_{v}}{P-P_{v}} \\
& P_{v}=P_{w}-\frac{\left(P-P_{w}\right)\left(T_{d b}-T_{w b}\right)}{1532-1.3\left(T_{w b}+273.15\right)} \\
& \phi=\frac{w\left(P-P_{v}\right)}{0.622 P_{v s}} \\
& h=T_{d b}+w\left(1.86 T_{d b}+2501.3\right) \\
& \operatorname{Ln}\left(\frac{P_{v s}}{2337}\right)=6789\left(\frac{1}{293.15}-\frac{1}{T_{d b}+273.15}\right)-5.031 \operatorname{Ln}\left(\frac{T_{d b}+273.15}{293.15}\right) \\
& \operatorname{Ln}\left(\frac{P_{v}}{2337}\right)=6789\left(\frac{1}{293.15}-\frac{1}{T_{d p}+273.15}\right)-5.031 \operatorname{Ln}\left(\frac{T_{d p}+273.15}{293.15}\right) \\
& \operatorname{Ln}\left(\frac{P_{w}}{2337}\right)=6789\left(\frac{1}{293.15}-\frac{1}{T_{w b}+273.15}\right)-5.031 \operatorname{Ln}\left(\frac{T_{w b}+273.15}{293.15}\right)
\end{aligned}
$$

Because $\mathrm{T}_{\mathrm{db}}$ and $w$ in point 4 are known, by solving the Eq. (8-15) simultaneously, $\mathrm{T}_{\mathrm{wb}}$ and all physical quantities of point 4 can be achieved.

4. Investigation of various parameters of desiccant wheel on reducing the ambient wet bulb temperature and selection of optimum quantities of them

In this section the air with $T_{d b}=32{ }^{\circ} \mathrm{C}$ and $w_{i}=18.4 \mathrm{~kg} / \mathrm{kg}$ will be used that is for Rasht climate design conditions in summer. The parameters of desiccant wheel are: $N=15 \mathrm{RPH}, d_{t}=0.2 \mathrm{~mm}, \mathrm{D}_{\mathrm{H}}=2.33 \mathrm{~mm}, T_{\text {reg }}=90^{\circ} \mathrm{C}, u=2 \mathrm{~m} / \mathrm{s}$ and the wheel has $20 \mathrm{~cm}$ width that E.Esfandiarinia and M.H. saidi [6] used in their article. In Figs.3-7, the change effects of various parameters of wheel on outlet wet bulb 
temperature from heat exchanger are illustrated. These results have been achieved by MATLAB software.

Fig. 3 shows that $T_{w b}$ will reduce by increasing the regeneration temperature. Desiccant wheel can be regenerated more by increasing the regeneration temperature. So the wheel can absorb much humidity and $\mathrm{T}_{\mathrm{wb}}$ will decrease.

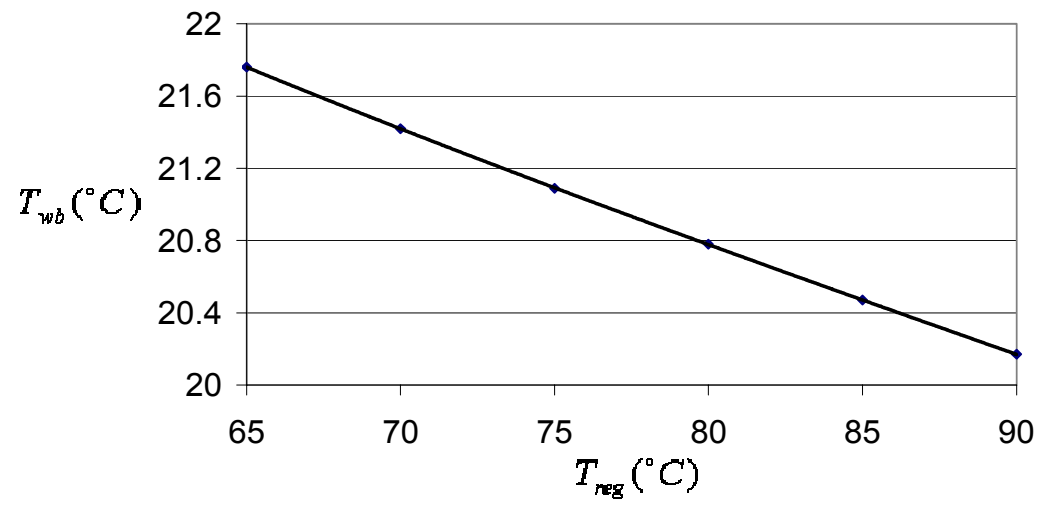

Fig.3: Effect of $T_{\text {reg }}$ on outlet $T_{w b}$ from heat exchanger

In about $\mathrm{N}=14 \mathrm{RPH}$, outlet wet bulb temperature from heat exchanger is minimum that can see in Fig.4. In slower speeds than optimum wheel speed, the humidity of desiccant material is high and it can not absorb more humidity. In higher speeds than optimum wheel speed, means that at the end of adsorption process, the desiccant wheel can still efficiently dehumidify the air stream.

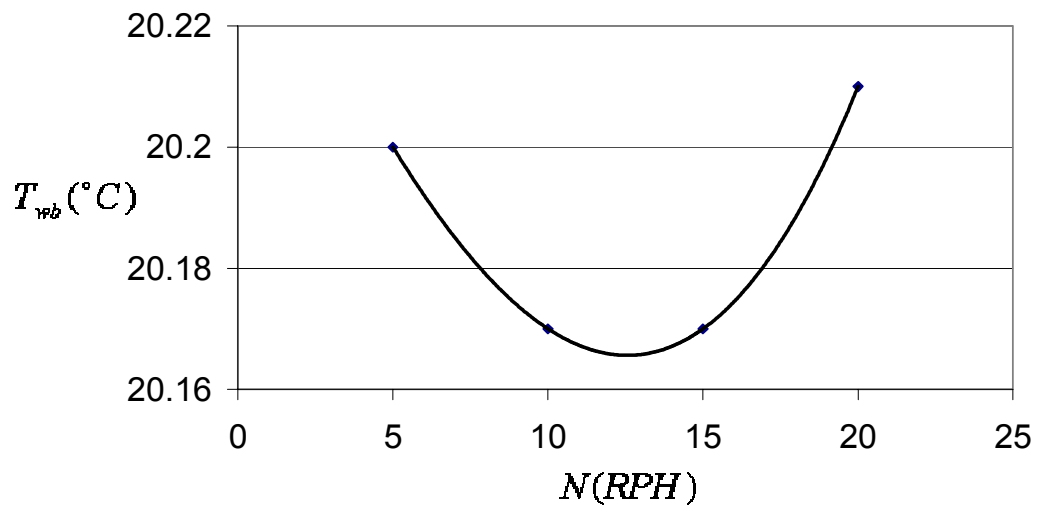

Fig.4: Wheel speed effect on outlet $T_{w b}$ from heat exchanger

With taking into consideration the Fig.5, an observation is made that by decreasing the thickness of the desiccant coating until about $d_{t}=0.15 \mathrm{~mm}$, the outlet wet bulb temperature from heat exchanger become minimum and in about $u=0.5 \mathrm{~m} / \mathrm{s}$, the outlet $T_{w b}$ from heat exchanger become the lowest that can be seen in Fig.6. 


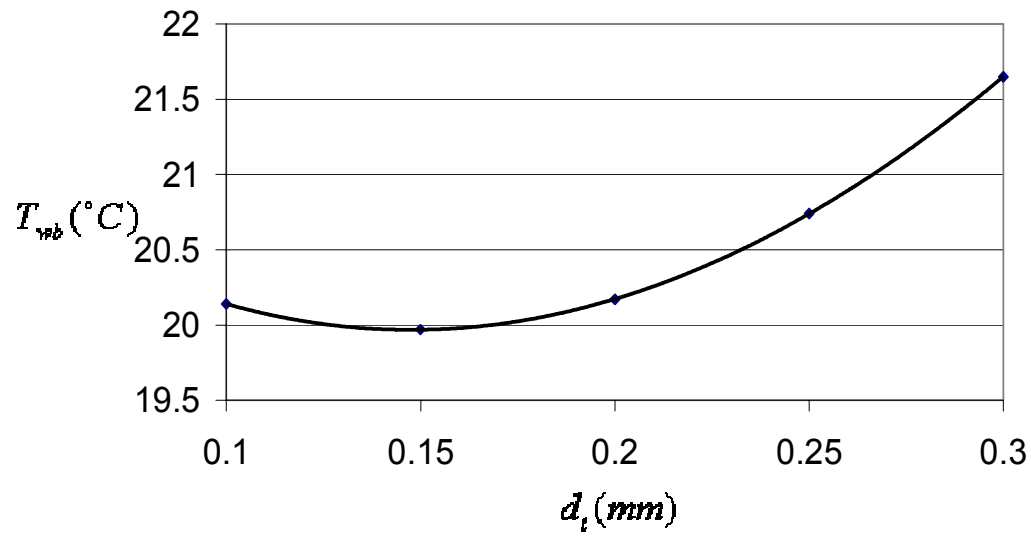

Fig.5: Effect of $d_{t}$ on outlet $T_{w b}$ from heat exchanger

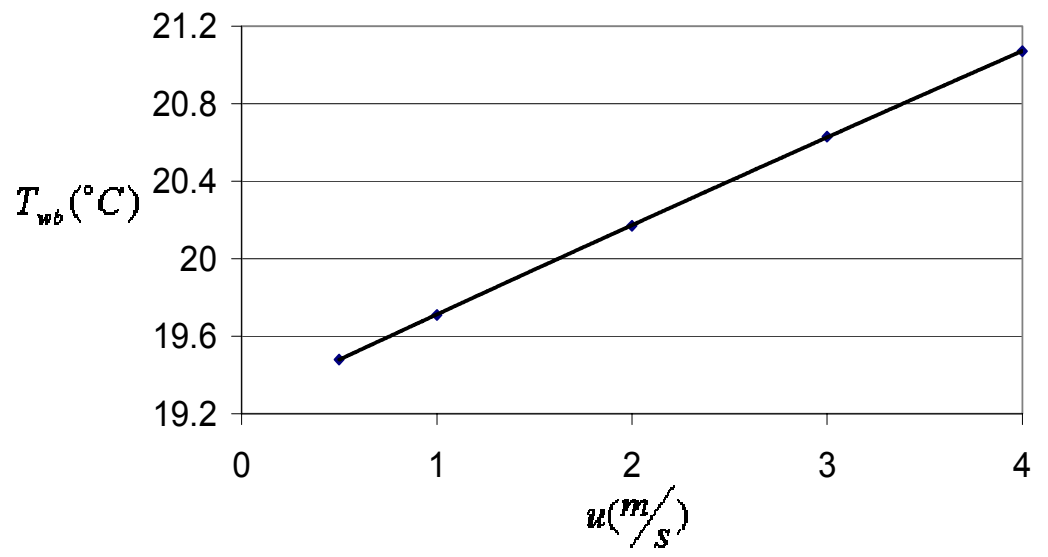

Fig.6: Effect of u on outlet $T_{w b}$ from heat exchanger

At the end, by taking into account the Fig.7, it can be seen that in about, $D_{H}=$ $2.51 \mathrm{~mm}$ the outlet $T_{w b}$ from heat exchanger become minimum. It can be deduced that $T_{w b}$ will increase by increasing or decreasing $D_{H}$ or $d_{t}$ from optimum quantities. Also $\mathrm{T}_{\mathrm{wb}}$ will decrease by reducing the air velocity because the air will lose its moisture more.

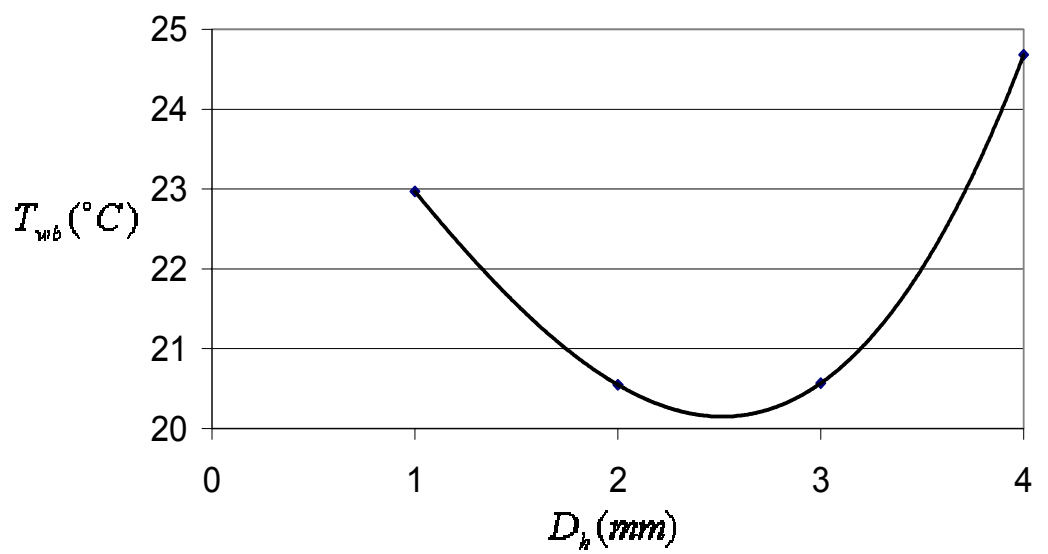

Fig.7: Effect of $D_{H}$ on outlet $T_{w b}$ from heat exchanger 
Entrance $T_{w b}$ to tower reduces from $25.73{ }^{\circ} \mathrm{C}$ to about $18.64{ }^{\circ} \mathrm{C}$ in Rasht by taking into consideration all the parameters of desiccant wheel in optimum quantity. Optimum parameters of desiccant wheel, outlet dry bulb and wet bulb temperature from heat exchanger by selecting desiccant wheel parameters in optimum quantities are shown in Table (1).

\section{Effect of cooling coil usage on decreasing the entrance $T_{w b}$ to tower}

In this section, effect of cooling coil usage will be investigated on outlet air temperature of heat exchanger and reducing the wet bulb temperature of that. As it is shown in Fig.2, cooling coil does not have any effect on humidity of outlet air of heat exchanger but its dry bulb temperature will reduce and its wet bulb temperature will decrease too. Because of this temperature reduction, tower performance will improve and the temperature of outlet water from that will decrease. After that, reduction of wet bulb temperature of outlet air from cooling coil will calculate for several cities of Iran for each surface temperature of cooling coil surface temperature.

Wet bulb temperature will be calculated with Eqs. (8-15). Outlet $T_{w b}$ from cooling coil for various surface temperatures is shown in Fig.8. It can be seen that $T_{w b}$ will reduce by decreasing $\mathrm{T}_{\mathrm{s}}$.

In Fig.8, surface temperature ( $\left.T_{s}\right)$ is selected based on $T_{s}<T_{3}$. Also for calculating $T_{4}$ from Eq.(7), $T_{3}$ is outlet air temperature from heat exchanger when all of the desiccant wheel parameters select in optimum quantity.

Table 1: Optimum parameters of desiccant wheel and outlet air temperature from heat exchanger with selection of desiccant wheel parameters in optimum quantity in several cities of Iran

\begin{tabular}{|l|c|c|c|c|c|c|c|c|c|}
\hline & Ghom & Khash & Garmsar & Khoramshahr & Maraghe & Ardebil & Ramsar & Rasht & Bandarabbas \\
\hline$H(\mathrm{~m})$ & 93 & 1394 & 825 & 10 & 1476 & 1314 & -20 & -7 & 10 \\
\hline$T_{d b}\left({ }^{\circ} \mathrm{C}\right)$ & 40 & 38.6 & 39 & 43 & 34.4 & 29.7 & 29.44 & 31.9 & 40 \\
\hline$w_{i}(\mathrm{~kg} / \mathrm{kg})$ & 0.009 & 0.01 & 0.012 & 0.013 & 0.014 & 0.014 & 0.017 & 0.018 & 0.026 \\
\hline$N_{\text {opt. }}(\mathrm{RPH})$ & 5 & 17 & 5 & 5 & 7.5 & 14 & 14 & 14 & 9 \\
\hline$\left(T_{\text {reg }}\right)_{\text {opt. }}\left({ }^{\circ} \mathrm{C}\right)$ & 90 & 90 & 90 & 90 & 90 & 90 & 90 & 90 & 90 \\
\hline$\left(D_{H}\right)_{\text {opt. }}(\mathrm{mm})$ & 2.5 & 2.51 & 2.51 & 2.51 & 2.51 & 2.5 & 2.51 & 2.51 & 2.51 \\
\hline$\left(d_{t}\right)_{\text {opt. }}(\mathrm{mm})$ & 0.13 & 0.14 & 0.14 & 0.13 & 0.14 & 0.15 & 0.15 & 0.15 & 0.14 \\
\hline$u_{\text {opt. }}(\mathrm{m} / \mathrm{s})$ & 0.5 & 0.5 & 0.5 & 0.5 & 0.5 & 0.5 & 0.5 & 0.5 & 0.5 \\
\hline$T_{\text {cww }}\left({ }^{\circ} \mathrm{C}\right)$ & 26.3 & 25.1 & 27.22 & 29 & 26.1 & 25.3 & 28.3 & 29 & N.A \\
\hline$\left(T_{\text {wb3 }}\right)_{\text {opt. }}\left({ }^{\circ} \mathrm{C}\right)$ & 19.33 & 16.73 & 18.43 & 22.34 & 16.8 & 14.04 & 17.1 & 18.6 & 26.6 \\
\hline$T_{3}\left({ }^{\circ} \mathrm{C}\right)$ & 42.33 & 41.62 & 41.6 & 45.5 & 37.15 & 32.84 & 33.05 & 36.13 & 44.23 \\
\hline
\end{tabular}




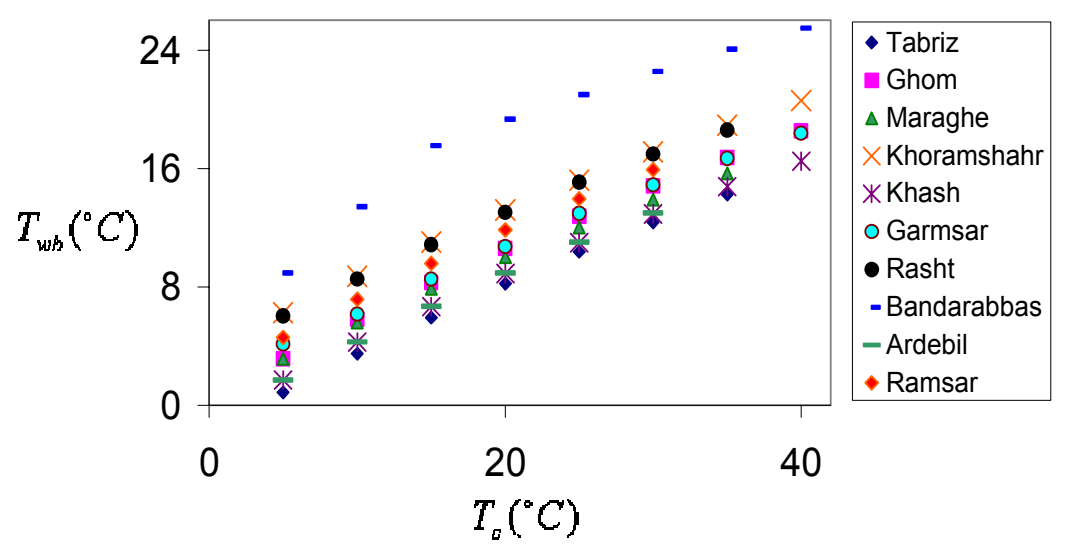

Fig.8: Effect of cooling coil surface on its outlet wet bulb Temperature $\left(T_{w b 4}\right)$ for several cities in Iran

6. Effect of reduction of $T_{w b}$ on outlet water temperature of cooling tower

In this section, effect of reduction of $T_{w b}$ will be investigated on decreasing the tower outlet water temperature. For this purpose, a nomograph will be used that has been offered by Perry [15]. A cooling tower with inlet water temperature equal to $35{ }^{\circ} \mathrm{C}(95 \mathrm{~F})$, outlet water temperature equal to $29.44{ }^{\circ} \mathrm{C}(85 \mathrm{~F})$ and ambient wet bulb temperature equal to $26.66{ }^{\circ} \mathrm{C}(80 \mathrm{~F})$ has been considered to foresight outlet water temperature.

In above mentioned conditions, tower range is equal to inlet water temperature minus outlet water temperature that is $5.56{ }^{\circ} \mathrm{C}(10 \mathrm{~F})$. In Fig.9, point $T_{w b}=26.6{ }^{\circ} \mathrm{C}$ $(80 \mathrm{~F})$ connect to cold water temperature equal to $29.44{ }^{\circ} \mathrm{C}(85 \mathrm{~F})$ that this line named original line. Now there can be sketched lines from each point from $T_{w b}$ axis and parallel to original line. The points that these lines cut the cold water temperature axis is the cold water temperatures that tower will produce under consideration $T_{w b}$ and initial tower range $\left(5.56^{\circ} \mathrm{C}\right)$. Naphon [12] showed that inlet water temperature has negligible effect on outlet water temperature. So even inlet water temperature would be equal to $35^{\circ} \mathrm{C}(95 \mathrm{~F})$, the outlet water temperature will be the quantities related to consideration $T_{w b}$.

With consideration the existing system in Fig.1, outlet water temperature from tower for various cooling coil surface temperature is illustrated in Fig.10. It can be seen that outlet cold water temperature will reduce by decreasing the cooling coil surface temperature.

\section{Optimum ratio of mass flowrate of water to dry air}

One of the most important discusses in cooling towers design is calculating required optimum ratio of mass flow rate of water to dry air. With selecting this 
parameter in right quantity, the tower efficiency will increase and the outlet cold water temperature will approach to wet bulb temperature so its temperature will reduce as much as possible. Söylemez [16] showed that for forced draft counter flow cooling towers, the optimum ratio of mass flow rate of water to dry air can be evaluated from the following equation:

$$
\left(\frac{L}{G}\right)_{o p t .}=\frac{C_{p, a}}{C_{w}}+\frac{h_{f g} \times 0.622 \times e^{18.6-\frac{5206.9}{T_{w}+273.15}} \times 5.2069 P}{C_{w}\left(T_{w}+273.15\right)^{2}\left[P \times 10^{-3}-e^{18.6-\frac{5206.9}{T_{w}+273.15}}\right]^{2}}
$$
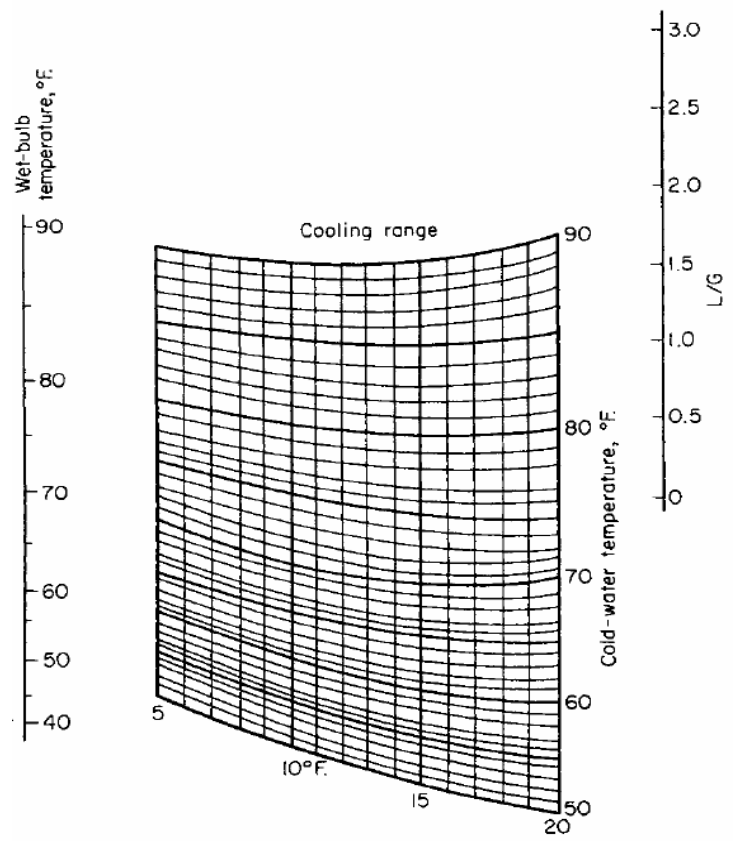

Fig.9: Nomograph of cooling tower characteristics [15]

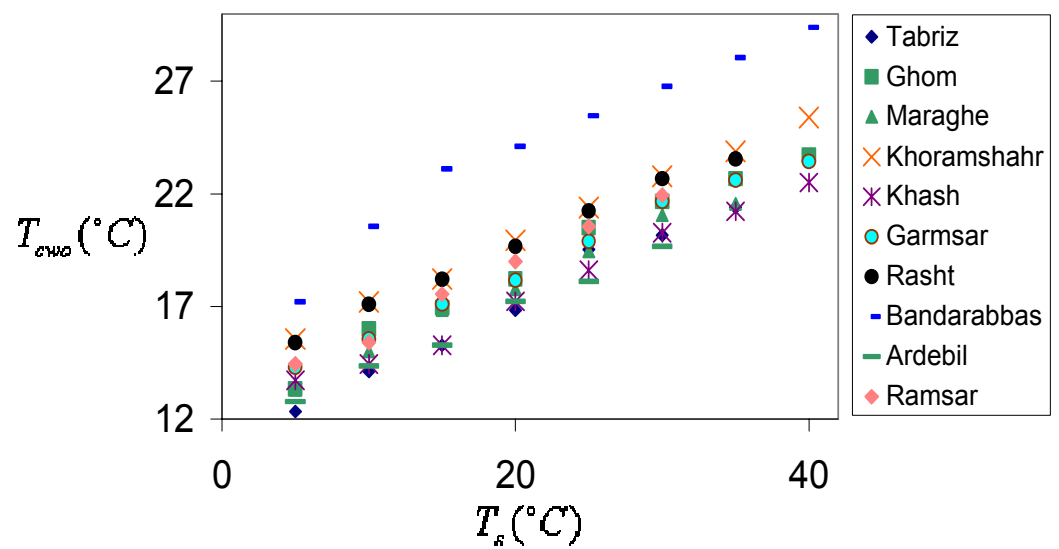

Fig.10: Quantities of outlet water temperature from tower for various cooling coil surface for selected cities in Iran

For a typical cooling tower problem, it is assumed that $C_{w}=4.184 \mathrm{~kJ} / \mathrm{kgK}, C_{p, a}=1.0035$ 
$\mathrm{kJ} / \mathrm{kgK}$ and $h_{f g}=2500 \mathrm{~kJ} / \mathrm{kg}$. $T_{w}$ is mean temperature of inlet and outlet water in ${ }^{\circ} \mathrm{C} . P$ is ambient pressure that can be determined by Eq. (17) that is given by [17]:

$P=101325\left(1-2.5577 \times 10^{-5} H\right)^{5.2599}$

The values of $(L / G)_{\text {opt. }}$ are plotted in Fig. 11 for different $T_{s}$ and cities. In Eq. (16), for calculating $T_{w}$, inlet water temperature to tower is equal to $35^{\circ} \mathrm{C}(95 \mathrm{~F})$ and outlet cold water temperatures are the quantities that are shown in Fig. 10.

It can be deduced there exists a local optimum value for the best cooling tower performance point of the counter current type for different location and average operating water temperature values. It is seen from Fig. 11 that $T_{s}$ and ambient conditions has an important effect on the optimum $L / G$ value. One can deduced that the optimum $L / G$ values decrease as the cooling coil temperature decreases. On the other hand, the effect of ambient conditions on $(L / G)_{o p t}$. is not clear because it depends on $T_{w b}$ and ambient pressure simultaneously.

The water mass flow rate must be increased for higher cooling coil temperature for the prescribed air flow rate. The correct selection of $L / G$ will lead to better effectiveness of the cooling tower.

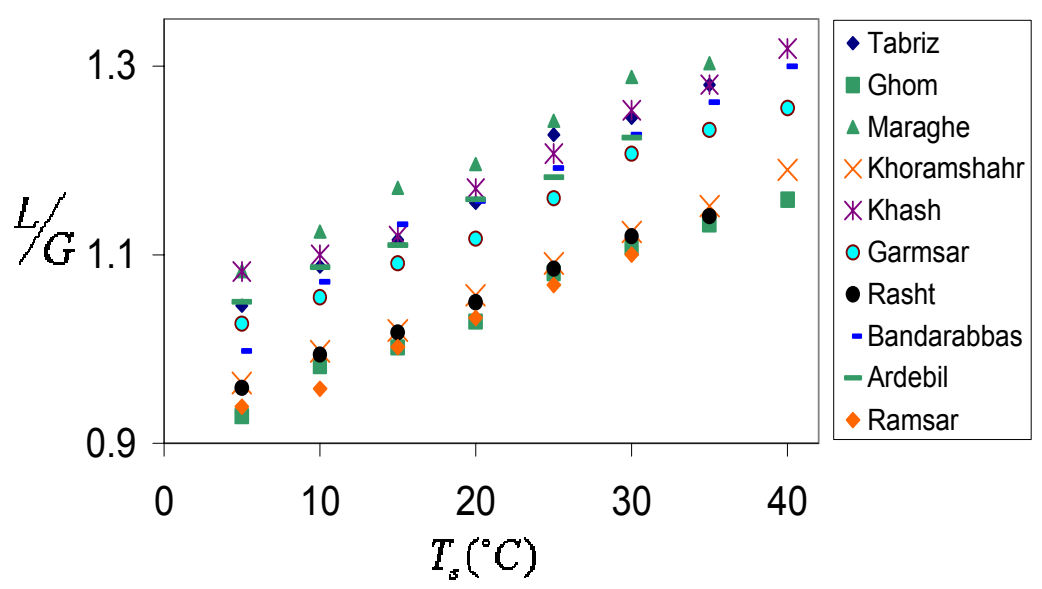

Fig.11: Optimum ratio of mass flow rate of water to dry air for various cooling coil surface temperature in selected cities in Iran

\section{Conclusion}

In this study, desiccant wheel was evaluated and optimum parameters of desiccant wheel calculated by taking into account the outdoor design temperature in summer. After that $T_{w b}$ of outlet air of heat exchanger was calculated by using all of wheel's parameters in optimum quantities, for selected cities of Iran. It can be deduced that this temperature will decrease from $25.73^{\circ} \mathrm{C}$ to $18.64^{\circ} \mathrm{C}$ for Rasht. After heat exchanger, a cooling coil used and outlet wet bulb temperature from coil and entering to tower for each coil surface temperatures calculated. It can be seen that $T_{w b}$ of cooling tower will reduce by decreasing the cooling coil temperature. This temperature is approximately same for cities that their $T_{w b}$ is close to each other. The maximum selected surface temperature is in any way that $T_{s}<T_{3}$. Outlet cold water temperature from tower for selected cities with regard to the time that considered system eliminate is calculated by computing the $\mathrm{T}_{\mathrm{wb}}$ of entrance air to tower for each $T_{s}$. It can be deduced that outlet water temperature will reduce compare to initial design quantity and this temperature is approximately same for 
cities that their $T_{w b}$ is near to each other. Also in this study, optimum ratio of water to air mass flow rate calculated for counter cooling tower. It can be seen that $(L / G)_{\text {opt. }}$ will reduce by decreasing the cooling coil temperature. In this ratio, outlet water temperature will reduce as much as possible.

Acknowledge

It is necessary to thanks from technical and financial supports of Pars Oil and Gas Company and National Iranian Oil Company.

\section{References}

(1)T.S.Kang,I.L.Maclain-Cross, "High performance solid desiccant cooling cycles", Transactions of ASME, vol. 111. pp. 176-183. 1989.

(2)I.L. Maclain-Cross, P.J Banks, "Coupled heat and mass transfer in regenerators prediction using an analogy with heat transfers", International Journal of Heat and Mass Transfer, vol.15, pp. 1225-1242, 1972.

(3)P.J. Banks, "Coupled equilibrium heat and single adsorbate transfer in fluid flow through a porous medium-2: predictions for a silica-gel air drier", Chemical Engineering Science, vol.27. pp. 1157-1169. 1972.

(4)W.Zheng, W.M.Worek, "Numerical simulation of combined heat and mass transfer process in a rotary dehumidifier", Numerical Heat Transfer Part A, vol. 23. pp. 211-232. 1993.

(5)H.M.Henning, T.Erpenbeck, Hindenberg, I.S.Santamiria, "The potential of solar energy use in desiccant cooling cycles", International Journal of Refrigeration vol. 24. pp. 220-229, 2001.

(6)F. Esfandiari Nia, D. V. Paassen, M. H. Saidi, "Modeling and simulation of desiccant wheel for air conditioning", International Journal of Energy and Buildings, vol. 38, pp. 1230-1239, 2006.

(7)M. H. Saidi, S. Vazirifard, "Hybrid Desiccant Cooling System", ASHRAE Journal vol. 49, Jan. 2006.

(8)H.Pasdarshahri, Q.Heidarinejad, S.Delphani, "Desiccant cooling system and effective parameters evaluation on its performance ", Mechanical Engineering Conference, Iran, 2007.

(9)S.S.Kachhwaha, P.L.Dhar, S.R.Kale, "Experimental studies and numerical simulation of evaporative cooling of air with a water spray", Heat and Mass Transfer Conference, India, 1997.

(10)S.P.Fisenko, A.I. Petruchik, A.D,Solodukhim, "Evaporating Cooling of Water in a Natural draft Cooling tower", International Journal of Heat and Mass Transfer, vol.45, pp. 4683-4694, 2002

(11)J. R. Khan, B. A. Qureshi, S. M. Zubair, "A comprehensive design and performance evalution study of counter flow wet cooling towers", International Journal of Refrigeration, vol. 27, pp. 914, 2004.

(12)Pairarn Naphon, "Study on the heat transfer characteristics of an evaporative cooling tower", International Communications in Heat and Mass Transfer, vol. 32, pp. 1066-1074, 2005.

(13)Guang-Yu Jin, Wen-Jian Cai, Lu Lu, Eng Lock Lee, Andrew Chiang", A simplified modeling of mechanical cooling tower for control and optimization of HVAC systems", International Journal of Energy Conversion and Management, vol. 48, pp. 355-365, 2007.

(14)M. A. AL-Nimr, B. A. Abu Nabah, M. Naji, “A Novel summer air conditioning 
system”, International Journal of Energy Conversion and Management, vol. 43, pp. 1911-1921, 2002.

(15)Don W.Green, Robert H.Perry, Perry's chemical engineers', McGraw Hill. Eighth Edition.

(16)M. S. Söylemez, "On the optimum performance of forced draft counter flow cooling tower", International Journal of Energy Conversion and Management, vol. 45, pp. 2335-2341, 2004.

(17)Zhiming Gao, Viung C. Mei, John j. Tomlinson, "Theoretical analysis of dehumidification process in desiccant wheel", International Journal of Heat and Mass Transfer, vol. 41, pp. 1033-1042, 2005. 